\title{
Atık Isı Geri Kazanım Sistemleri ve Isıl Verim Parametrelerinin Deneysel İncelenmesi
}

\author{
Gamze Karanfil ${ }^{1,2^{* *}}$, Selmin Ener Ruşen ${ }^{1,2}$, Şeyma Nur Poyraz ${ }^{1}$, Mustafa Can ${ }^{1}$ \\ ${ }^{1}$ Karamanoğlu Mehmetbey Üniversitesi, Mühendislik Fakültesi, Enerji Sistemleri Mühendisliği Bölümü, Karaman, Türkiye \\ ${ }^{2}$ Karamanoğlu Mehmetbey Üniversitesi, Enerji Verimliliği Araştırma ve Uygulama Merkezi, Akademik Enerji Araştırma Grubu (AKEN), Karaman, Türkiye (ORCID: \\ 0000-0002-7941-9853: 0000-0003-3389-5739)
}

(İlk Geliş Tarihi 18 Mart 2020 ve Kabul Tarihi 23 Mayıs 2020)

(DOI: 10.31590/ejosat.705762)

ATIF/REFERENCE: Karanfil, G., Ruşen, S. E., Poyraz, Ş. N. \& Can, M. (2020). Atık Isı Geri Kazanım Sistemleri ve Isıl Verim Parametrelerinin Deneysel İncelenmesi. Avrupa Bilim ve Teknoloji Dergisi, (19), 127-137.

$\ddot{\mathbf{O z}}$

Günümüzde enerjiye olan ihtiyacın artması, kullanılan fosil enerji kaynaklarının sınırlı miktarda ve çevreye zararlı olması alternatif enerji kaynakların yaygınlaşmasına sebep olmuştur. Bu alternatif enerji kaynakları arasında en güvenilir, kolay ulaşılabilir ve ucuz olan enerji kaynağı, enerjinin verimli kullanılması olarak tüm dünyada kabul görmektedir. Bu bağlamda enerji verimliliği, üretim kalitesi ve miktarının düşmesine sebebiyet vermeden enerji tüketiminin azaltılması olarak tanımlanmaktadır. Farklı kaynaklardan elde edilen enerjinin büyük bir kısmı sanayi sektöründe kullanılmaktadır. Sanayide enerjinin verimli kullanılması, kayıp ve kaçakların önlenmesi ve atık enerjinin geri kazanımı gibi yöntemlerle enerji maliyetinin düşürebileceği ve verimliliğinin arttırılacağı öngörülmektedir. Aynı zamanda enerjinin verimli kullanılması ülke ekonomisine ve çevrenin korunmasına da büyük katkı sağlayacaktır. Sanayi sektöründe, özellikle atık ısının kullanılmaması kayıp enerjinin en önemli sebeplerinden biridir. Bu çalışmada atık 1sı geri kazanım sistemleri tanımlanarak, sanayide en çok kullanılan iki tip atık 1sı geri kazanım sisteminin (1sı tekeri ve reküparatör) 1sıl verimi üzerindeki etki eden parametreler deneysel olarak incelenmiştir. İncelenen sistemde verimliliğin arttırılması amacıyla optimum şartların belirlenmesi için Taguchi metodu kullanılmış ve analizler gerçekleştirilerek sonuçlar yorumlanmışırı. Isı tekeri için optimum koşullar \% 100 1sı tekeri devir hızı, \% 60 Fan 1 hızı ve \% 80 Fan 2 hızı olarak bulurken, reküparatör için $50^{\circ} \mathrm{C}$ hava giriş sıcaklığı, \% 60 Fan 1 hızı ve \% 80 Fan 2 hızı olarak bulunmuştur. Doğrulama deneyleri sonucunda elde edilen en yüksek verim değerleri 1sı tekeri ve reküparatör sistemleri için sırasıyla \% 97 ve \% 73 olarak hesaplanmıştır. Bu değerler, yapılan tüm deneyler içerisinde en yüksek verim değerleri olarak kaydedilmiş ve Taguchi metodunun uygulanabilirliği ile yapılan analizlerin doğruluğunu göstermiştir.

Anahtar Kelimeler: Enerji, Enerji Verimliliği, Atık Isı, Taguchi Metodu

\section{Experimental Investigation of Waste Heat Recovery Systems and Heat Yield Parameters}

\begin{abstract}
Today, the energy needs are increasing, but the limited amount of fossil energy resources existing and its harmful to the environment has led to the spread of alternative energy sources. The most reliable, easily accessible and inexpensive energy source among these alternative energy sources is accepted worldwide as the efficient use of energy. In this context, energy efficiency is defined as the reduction of energy consumption without causing a decrease in production quality and quantity. Most of the energy obtained from different sources is used in the industry sector. It is anticipated that energy efficiency can be reduced and efficiency will be increased through methods such as efficient use of energy in the industry, prevention of losses and leaks and recovery of waste energy. At the same time, efficient use of energy will make a great contribution to the economy of the country and the protection of the environment. In the industrial sector, especially not using waste heat is one of the most important causes of lost energy. In this study, the waste heat recovery systems are defined and the parameters affecting the thermal efficiency of the two types of waste heat recovery systems (heat wheel and recuperator) most used in the industry are investigated experimentally. Taguchi method was used to determine the optimum conditions in order to increase efficiency in the system examined, and the results were interpreted by analyzing. The optimum conditions for the heat wheel are found as $100 \%$ heat wheel turnover rate, $60 \%$ Fan 1 speed and $80 \%$ Fan 2 speed, while the recuperator is $50{ }^{\circ} \mathrm{C}$ air inlet temperature, 60\% Fan 1 speed and 80\% Fan 2 speed. The highest efficiency values obtained as a result of verification experiments were calculated as $97 \%$ and $73 \%$ for heat wheel and recuperator systems, respectively. These values were recorded as the highest efficiency values in all experiments and showed the accuracy of the analyzes performed with the applicability of the Taguchi method.
\end{abstract}

Keywords: Energy, Energy Efficiency, Waste Heat, Taguchi Method

* Sorumlu Yazar: Karamanoğlu Mehmetbey Üniversitesi, Mühendislik Fakültesi, Enerji Sistemleri Mühendisliği Bölümü, Karaman, Türkiye, ORCID: 0000-0002-7941-9853, gamzekaranfi186@.gmail.com 


\section{Giriş}

Artan enerji talebini karşılamak için hâlihazırda kullanılan fosil kaynakların sürdürülebilir olamaması ve çevresel olumsuz etkileri nedeniyle alternatif enerji kaynakları günümüzde giderek yaygınlaşmıştır. Alternatif enerji kaynakları arasında değerlendirilen enerji verimliliği ise ucuz, temiz ve kolay uygulanabilmesi nedeniyle dikkat çekmektedir. Bu bağlamda pek çok ülkede enerjinin verimli kullanılması ve çevrenin korunmasında dair planlamalar, kanun ve yönetmelikler uygulanmaktadır. Ülkemizde ise, 2 Mayıs 2007 tarih ve 26510 sayılı Resmî gazete'de yayımlanarak yürürlüğe giren, 5627 sayılı Enerji Verimliliği Kanunu ve 25 Ekim 2008 tarih ve 27035 sayılı Enerji Kaynakları ve Enerjinin Kullanımında Verimliliğin Artırılmasına Dair Yönetmelik gereğince enerjinin her alanda etkin kullanımı ve verimliliğinin artırılması belirtilmiştir (Ener Rusen ve Koç, 2019).

Enerjinin en yoğun kullanıldığı alanlar arasında sanayi sektörü tüm dünyada önemli bir yerde bulunmaktadır. Bu bağlamda, küresel ısınmanın önlenmesi ve dolayısıyla sera gazı salınımlarının azaltılması için sanayi sektöründeki enerjinin kullanım biçimi incelenmelidir. Dünya çapındaki nihai enerjinin yaklaşık \% 38'i sanayide kullanmaktadır. Bu nedenle endüstriyel proseslerin enerji tüketimi mümkün olduğunca azaltılmalıdır (Brueckner vd., 2014). Günümüzde, tüm dünyada sera gazı salınımını azaltmak için yapılan çalışmalar ve çıkarılan mevzuatlar nedeniyle özellikle sanayideki enerji tüketiminin azaltılması anahtar faktörlerden biri haline gelmiştir. Bunun yanı sıra, enerji verimliliğindeki iyileşmelerin daha düşük işletme maliyeti ve artan karlılık ile sonuçlandığı da bilinmektedir (Varga ve Palotai, 2017). Ancak çoğu zaman 1sıl sistemleri optimize edilmiş işletmelerde bile yüksek sıcaklıkta olan atık 1sı dışarı atılmaktadır. Atık ısının değerlendirilmesi için doğrudan kullanım sağlayan veya egzoz ısı teknolojileri uygulayarak isı veya elektrik üretmek için kullanılan uygulamalar vardır (Brueckner vd., 2014).

Sanayide kullanılan enerjinin neredeyse \% 26’l1k bir kısmı sıcak gazlar ve sıvılar olarak atılmaktadır. Kaybedilen bu enerji, atık 1S1 geri kazanımıyla büyük ölçüde azaltılabilir. Atık 1Sı geri kazanım sistemlerine yapılacak yatıımın asgari sürede kendini amorti edebilmesi rekabet ortamında avantajlar sağlamaktadır (Çomaklı ve Terhan, 2011). Endüstriyel atık ısı geri kazanım sistemleri önemli ölçüde enerji tasarrufu ve sera gazı salınımlarında önemli azalmalar sağlayabilen sistemlerdir (Editorial, 2018). Bu bağlamda, endüstriyel süreçlerde atık ısı geri kazanım sistemlerinin kullanılması yakıt tüketimini azaltmak, zararlı gaz salınımlarını azaltmak ve üretim verimliliğini artırmak için önemli araştırma alanlarından biri olmuştur (Jouhara vd., 2018; Ener Rusen, 2019). Tüm bu avantajlar göz önüne alındığında, endüstriyel işletmelerin kendilerine uygun atık ısı geri kazanım sistemlerini kurmalarının önemi açıkça görülmektedir.

Geri kazanılmak istenen atık ısı kaynağı belirlendikten sonra bu ısının nerede ve ne amaçla kullanılacağı tespit edilerek geri kazanım ile faydalanılacak 1sı miktarı ve uygun olan sistem seçilmelidir. Ancak geri kazanılmak istenen atık ssı miktarı ne kadar fazla olursa kullanılacak sistemin kapasitesi ve buna bağlı olarak da yatırım maliyeti yüksek olacaktır. Atık ısı geri kazanım sisteminin belirlenmesi etkileyen temel faktörlerin başında, akışkanların sıcaklıkları, 1sı transfer kapasitesi, akışkanları nitelikleri ve hacimsel debileri gelmektedir (Uysal, 2019).

Sanayide genellikle karşılaşılan hava-hava (gaz-gaz) tipi 1sı geri kazanımı için çeşitli teknikler bulunmaktadır (Ener Rusen vd., 2018). En yaygın hava-hava tipi ısı geri kazanımı cihazları 1sı tekerleri, plakalı 1sı değiştiricileri (reküparatörler gibi) ve 1sı borularıdır. Isı tekerleri sistemlerinde, biri sıcak atık hava diğeri ise soğuk hava içeren iki paralel kanalın üzerine yerleştirilmiş dönen gözenekli bir disk kullanılmaktadır. Yüksek ısı kapasiteli bir malzemeden oluşan bu disk, iki kanal arasında döner ve 1sıyı sıcak hava kanalından soğuk hava kanalına aktarır. Isı tekerleri kullanımı genellikle yüksek sıcaklıkların yarattığı olumsuz termal stres nedeniyle düşük ve orta sıcaklıktaki uygulamalarla sınırlıdır (Manikantha vd., 2017; Shahsavar ve Khanmohammadi, 2019). Reküparatörler ise paralel akışl1, çapraz akışlı ve zıt akışlı 1sı değiştiricileri olarak sınıflandırılır. En yaygın reküparatörler, çapraz akış plakalı 1sı değiştiricilerdir (Karanfil vd., 2019) Taze ortam havası ve atık nemli kirli hava bu tip ısı değiştiricisinde birbirine karışamaz, çünkü bu hava akışları farklı kanallardan geçmektedir (Oğulata, 2004).

Yapılan bu çalışmada, sanayide en çok karşılaşılan hava-hava tipi ısı geri kazanım cihazı olan 1sı tekeri ve reküparatörün 1sıl verimleri üzerinde akış hızları, egzoz havası sıcaklığı ve devir sayısı gibi parametrelerin etkisi araştırılmışıtır. Isıl verimleri etkileyen bu parametrelerin etkisini bir arada incelemek ve en etkin parametreleri belirlemek için Taguchi optimizasyon metodu kullanılmıştır. Taguchi metodunun sonuçlarının desteklenmesi ve daha detaylı analiz edilmesi için varyans analizi (ANOVA) gerçekleştirilmiştir.

\section{Materyal ve Metot}

Hava-hava tipi ısı geri kazanım cihazları olan ısı tekeri ve reküparatörün ısıl verimleri üzerine etki eden parametrelerin incelenmesi için Karamanoğlu Mehmetbey Üniversitesi Enerji Verimliliği Eğitim Laboratuvarı'nda bulunan ve Şekil 1'de verilen atık 1sı geri kazanım ünitesi kullanılmıştır. Deneysel incelemede kullanılan atık ısı geri kazanım ünitesinde toplam 4 tane geri kazanım sistemi bulunmaktadır. Bunlar: 1sı tekeri, sulu 1sı değiştiricisi (ekonomizer), 1S1 pompası, plakalı 1sı değiştiricisi (reküparatör)'dir. Ayrıca sistemde bir adet 1sitıcı, 2 adet fan, 4 adet damper bulunmaktadır. Sistem üzerinde toplam 11 ayrı noktada sıcaklık ve nem kontrolü yapılabilmektedir. Deneysel incelemede kullanılan atık ısı geri kazanım ünitesinin şematik gösterimi, elemanları ve sıcaklık-nem ölçüm 
noktaları detaylı olarak Şekil 1'de verilmektedir. Şekil 1'de ilk sıcaklık T-1 ve nem H-1, son sıcaklık T-11 ve nem H-11 olmak üzere ölçüm noktaları sırasıyla gösterilmiştir.

Sistemde deneye başlamadan önce kontrol ekranından ilgili deney parametreleri (sıcaklık, fan1 ve fan2 hızı, 1sı tekeri devir hızı vb.) ayarlanmıştır. Yapılacak deneye ilişkin ayarlamalar yapıldıktan sonra, 1sıtııı ve fanlar açılmıştır. Sistem kararlı hale geldikten sonra ölçüm değerleri kontrol ekranından okunarak kaydedilmiştir. Isı tekeri ölçümlerinde karşıt akış sağlanması için üst ve alt damperler açık tutulurken, reküparatör ölçümlerinde çapraz akışı sağlayabilmek için yan kısımdaki damperler açılmıştır.

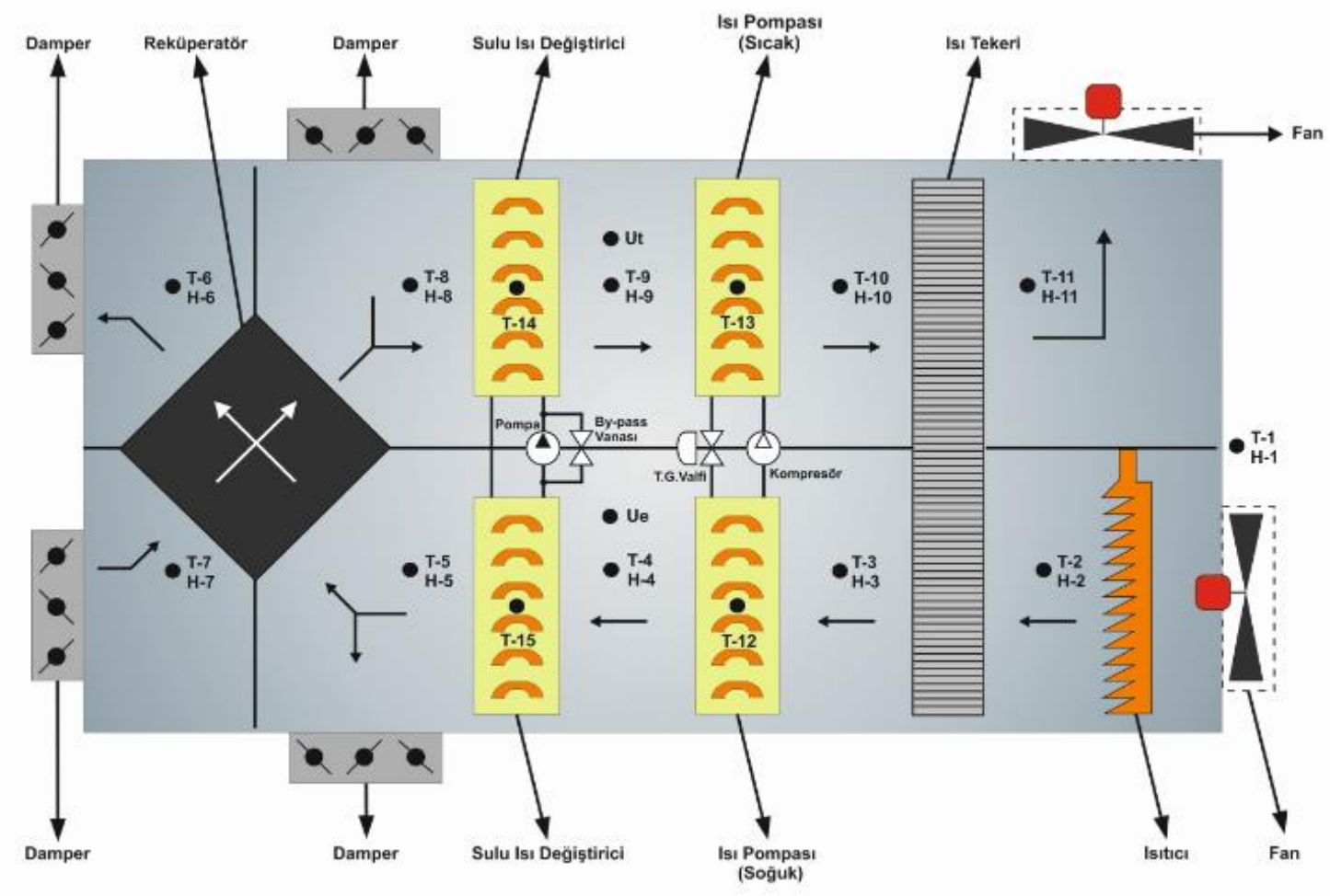

Şekil 1. Atık 1sı geri kazanım ünitesinin şematik gösterimi (http://kmu.edu.tr/akademikenerji)

Atık 1sı geri kazanım sisteminin (1sı değiştiricisinin) performansının saptanması için toplam 1sı geçişini belirten bir bağıntıya ihtiyaç duyulmaktadır. Isı kaybının olmadığını kabul ederek; termodinamik ve ısı geçiş prensiplerini kullanarak bir ısı değiş̧tiricisi için Denklem (2.1) yazılabilmektedir (Çengel, 2011):

$Q=U \cdot A . . \Delta T_{\mathrm{LM}}$

Burada $U=$ Toplam 1sı transfer kat sayısı $\left(W / m^{20} \mathrm{C}\right), A=$ Isı transfer yüzeyi $\left(\mathrm{m}^{2}\right)$ ve $\Delta T_{\mathrm{LM}}=$ Logaritmik ortalama sıcaklık farkı $\left({ }^{0} \mathrm{C}\right)$ şeklindedir. Isı değiştiricisinden çevreye $1 \mathrm{~s} 1$ kaybı olmadığı durumda, kinetik ve potansiyel enerjiler ihmal edildiğinde farklı sıcaklıkta bulunan iki akışkanın ısı transfer denkliği Denklem (2.2) ile verilmektedir.

$\dot{\mathcal{Q}}=\dot{m}\left(h_{g}-h_{c}\right)$

Burada $\dot{m}=$ Akışkanın kütlesel debisi $(\mathrm{kg} / \mathrm{s})$ ve $h_{g}, h_{c}=$ Akışkanın sıcaklığa bağlı giriş ve çıkış entalpileri $(\mathrm{kj} / \mathrm{kg})$ şeklindedir.

Bu denklemi sıcak ve soğuk akışkan için yazarsak, sıcak akışkandan soğuk akışkana gerçekleşen ısı transferi Denklem (2.3) elde edilmektedir:

$\dot{Q}_{1}=\dot{m}_{\text {slcak }}\left(h_{\text {slcak }, g}-h_{\text {slcak }, \zeta}\right)$

Soğuk akışkandan sıcak akışkana gerçekleşen ısı transferi ise Denklem (2.4) kullanılarak bulunur.

$\dot{Q}_{2}=\dot{m}_{s o g ̆ u k}\left(h_{s o g ̆ u k, c ̧}-h_{s o g ̆ u k, g}\right)$

Burada, $\dot{m}_{\text {sıcak }}, \dot{m}_{\text {ssoğuk }}=$ Sıcak ve soğuk akışkanın kütlesel debileri $(\mathrm{kg} / \mathrm{s}), h_{\text {sıcak }, g}, h_{\text {sıcak,ç}}=$ Sicak akışkanın giriş ve çııı̧̧ entalpileri $(\mathrm{kj} / \mathrm{kg})$ ve $h_{s o g ̆ u k, g}, h_{s o g ̆ u k, c}=$ Soğuk akışkanın giriş ve çıkış entalpileri $(\mathrm{kj} / \mathrm{kg})$ olarak tanımlanmaktadır. 
Denkliklerde kullanılan havanın kütlesel debisi ise Denklem (2.5) ve (2.6) kullanılarak hesaplanabilir;

$\dot{m}_{\text {slcak }}=\dot{V}_{1} / v_{g}$

$\dot{V}_{1}=A \cdot u$

Burada, $\dot{V}_{1}=$ Hacimsel debi $\left(\mathrm{m}^{3} / \mathrm{s}\right), A=$ Isı transfer yüzey alanı $\left(\mathrm{m}^{2}\right)$ ve $u=$ Akışkanın hızı $(\mathrm{m} / \mathrm{s})$ olmak üzere $V_{g}$; girişteki havanın özgül hacmidir ve birimi $\mathrm{m}^{3} / \mathrm{kg}^{\text {‘dir. }}$

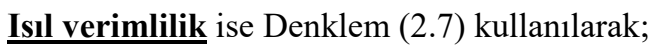

$\eta=\dot{\mathcal{Q}_{2}} / \dot{\mathcal{Q}_{1}}$

şeklinde bulunur. Akışkanın entalpi ve özgül hacim değerleri, giriş ve çıkış noktalarında ölçüm sırasında alınan kuru termometre sıcaklığı ve bağıl nem değerlerine bağlı olarak psikometrik diyagramdan okunmuştur.

\subsection{Isı Tekerinin Isıl Verimliliğinin Bulunması}

Deney sistemindeki parametreler ve literatürdeki çalışmalar ışı̆̆ında 1sı tekerinin atık 1sı geri kazanım verimini bulmak için belirlenen parametreler ve seviyeleri Tablo 1'de verilmiştir.

Tablo 1. Isı tekeri isıl verimliliği deney parametreleri

\begin{tabular}{cccc}
\hline & Devir Sayısı (\%) (A) & Fan 1 Hizı (\%) & Fan 2 Hizı (\%) \\
\hline 1 & 60 & 60 & 60 \\
2 & 80 & 80 & 80 \\
3 & 100 & 100 & 100 \\
\hline
\end{tabular}

Isı tekerinin 1sıl verimliliği için belirlenen deney parametreleri ve seviyeleri incelendiğinde 3 seviyeli 3 faktörden oluşan bir deney tasarımına ihtiyaç duyulduğu görülmektedir. Geleneksel yol tercih edildiğinde deney sayısının $3^{3}=27$ tane olması gerekmektedir. Deney sayısının azaltılması ve optimum sonuçların elde edilebilmesi için Taguchi tarafından gerçekleştirilen 9 denemeli L 9 ortogonal dizisi bu deney için seçilmiştir. Bu yöntem kullanılarak yapılması zorunlu olan 9 deney ile istenilen analizler gerçekleştirilmiş ve toplam 279=18 deneyin yapılmasına gerek kalmamıştır. 18 tane deneyin yapılması için geçecek süre ve maliyet kullanılmayarak tasarruf edilmiştir.

Tablo 2’te deneylerde kullanılan L9 ortogonal dizini verilmiştir. Bu tabloya göre parametreler sütunlara yerleştirilmiştir.

Tablo 2. L9 ortogonal dizini

\begin{tabular}{llll}
\hline & A & B & C \\
\hline 1 & 1 & 1 & 1 \\
2 & 1 & 2 & 2 \\
3 & 1 & 3 & 3 \\
4 & 2 & 1 & 2 \\
5 & 2 & 2 & 3 \\
6 & 2 & 3 & 1 \\
7 & 3 & 1 & 3 \\
8 & 3 & 2 & 1 \\
9 & 3 & 3 & 2 \\
\hline
\end{tabular}

Isı tekerinin 1sıl verimliliğinin hesaplanması için belirlenen sistem parametrelerinin sütunlara yerleşimi sırasıyla Tablo 3'te verilmiştir. 
Tablo 3. Isı tekeri sistemi deney tasarımı

\begin{tabular}{cccc}
\hline Deney No & A & B & C \\
\hline 1 & 60 & 60 & 60 \\
2 & 60 & 80 & 80 \\
3 & 60 & 100 & 100 \\
4 & 80 & 60 & 80 \\
5 & 80 & 80 & 100 \\
6 & 80 & 100 & 60 \\
7 & 100 & 60 & 100 \\
8 & 100 & 80 & 60 \\
9 & 100 & 100 & 80 \\
\hline
\end{tabular}

\subsection{Reküparatörün Isıl Verimliliğinin Bulunması}

Deney sistemindeki parametreler ve literatürdeki çalışmalar ışı̆̆ında reküparatörün atık 1sı geri kazanım verimini bulmak için belirlenen parametreler ve seviyeleri Tablo 4’te verilmiştir.

Tablo 4. Reküparatör isll verimliliği deney parametreleri

\begin{tabular}{cccc}
\hline & Hava Giriş Sıcaklığı $\left({ }^{\mathbf{0}} \mathbf{C}\right)(\mathbf{A})$ & Fan 1 Hızı (\%) & Fan 2 Hızı (\%) \\
\hline 1 & 30 & 60 & 60 \\
2 & 40 & 80 & 80 \\
3 & 50 & 100 & 100 \\
\hline
\end{tabular}

Reküparatörün 1sıl verimliliği için belirlenen deney parametreleri ve seviyeleri incelendiğinde 3 seviyeli 3 faktörden oluşan bir deney tasarımına ihtiyaç duyulduğu görülmektedir. Benzer şekilde, geleneksel yol tercih edildiğinde deney sayısı $3^{3}=27$ olmaktadır. Taguchi tarafindan gerçekleştirilen 9 denemeli $\mathrm{L}_{9}$ ortogonal dizisi bu deney için de seçilmiştir. Yapılacak 9 deney ile istenilen analizler yapılabilmektedir ve 27-9=18 deney yapmak için geçen süre ve maliyetten tasarruf edilmiştir.. Deney tasarımı için yine Tablo 2 'te verilen modifiye $\mathrm{L}_{9}$ ortogonal dizini kullanılmıştır.

Reküparatörün 1sıl verimliliğinin hesaplanması için belirlenen sistem parametrelerinin sütunlara yerleşimi sırasıyla Tablo 5 'te verilmiştir.

Tablo 5. Reküparatör sistemi deney tasarımı

\begin{tabular}{cccc}
\hline Deney No & A & B & C \\
\hline 1 & 30 & 60 & 60 \\
2 & 30 & 80 & 80 \\
3 & 30 & 100 & 100 \\
4 & 40 & 60 & 80 \\
5 & 40 & 80 & 100 \\
6 & 40 & 100 & 60 \\
7 & 50 & 60 & 100 \\
8 & 50 & 80 & 60 \\
9 & 50 & 100 & 80 \\
\hline
\end{tabular}

\section{Araştırma Sonuçları ve Tartışma}

\subsection{Isı Tekerinin Isıl Verimlilik Sonuçları}

Isı tekeri sistemi için Taguchi optimizasyon metodu ile belirlemiş olan deney tasarımı neticesinde gerçekleştirilen deneylerin ölçüm sonuçları Tablo 6'da verilmiştir. Tabloda bulunan $\mathrm{T}$ ve $\mathrm{H}$ ölçümleri sırasıyla, Şekil 1'de verilen noktalardaki kuru termometre sıcaklıklarını ve bağıl nemleri göstermektedir. $u_{t}$ taze hava hızını ve $u_{e}$ egzoz hava hızını vermektedir. 
Avrupa Bilim ve Teknoloji Dergisi

Tablo 6. Isı tekeri sistemi ölçüm sonuçları

\begin{tabular}{|c|c|c|c|c|c|c|c|c|c|}
\hline Deney no & 1 & 2 & 3 & 4 & 5 & 6 & 7 & 8 & 9 \\
\hline Devir sayısı (\%) & 60 & 60 & 60 & 80 & 80 & 80 & 100 & 100 & 100 \\
\hline Fan1 Hizı (\%) & 60 & 80 & 100 & 60 & 80 & 100 & 60 & 80 & 100 \\
\hline Fan2 Hızı (\%) & 60 & 80 & 100 & 80 & 100 & 60 & 100 & 60 & 80 \\
\hline $\mathrm{T}_{2}\left({ }^{\circ} \mathrm{C}\right)$ & 41 & 39,5 & 40,1 & 39,9 & 39,3 & 39,0 & 39,1 & 39,1 & 39,2 \\
\hline $\mathrm{H}_{2}(\%)$ & 15,2 & 12,9 & 15,6 & 11,6 & 12,8 & 13,0 & 12,1 & 11,9 & 13,3 \\
\hline $\mathrm{T}_{3}\left({ }^{\circ} \mathrm{C}\right)$ & 33,3 & 28,8 & 30,9 & 26,5 & 27,6 & 32,0 & 26,0 & 31,1 & 30,1 \\
\hline $\mathrm{H}_{3}(\%)$ & 23,1 & 23,6 & 25,9 & 24,1 & 24,5 & 19,7 & 24,5 & 19,5 & 22,1 \\
\hline $\mathrm{T}_{10}\left({ }^{\circ} \mathrm{C}\right)$ & 31,2 & 26,0 & 27,7 & 25,2 & 25,2 & 25,8 & 25,2 & 26,0 & 26,0 \\
\hline $\mathrm{H}_{10}(\%)$ & 23,6 & 26,9 & 30,1 & 25,4 & 27,4 & 26,7 & 25,0 & 24,5 & 26,9 \\
\hline $\mathrm{T}_{11}\left({ }^{\circ} \mathrm{C}\right)$ & 40,9 & 34,4 & 37,4 & 34,8 & 34,7 & 35,5 & 33,1 & 35,7 & 37,0 \\
\hline $\mathrm{H}_{11}(\%)$ & 15,4 & 17,3 & 18,3 & 15,6 & 16,8 & 16,2 & 16,8 & 14,9 & 15,4 \\
\hline $\mathbf{u}_{t}(\mathbf{m} / \mathbf{s})$ & 0,38 & 0,61 & 0,68 & 0,64 & 0,83 & 0,29 & 0,80 & 0,30 & 0,56 \\
\hline$u_{e}(m / s)$ & 0,57 & 0,75 & 0,88 & 0,58 & 0,75 & 1,00 & 0,58 & 0,81 & 0,90 \\
\hline
\end{tabular}

Taguchi optimizasyon metodu ile oluşturan deney tasarımı neticesinde, belirlenen parametreler ve seviyelerine göre deneyler gerçekleştirilmiş ve elde edilen veriler doğrultusunda psikrometrik diyagram kullanılarak entalpi ve özgül hacim ( $v_{g t}$ taze havanın özgül hacmini ve $v_{g e}$ egzoz havasının özgül hacmini göstermektedir) değerleri okunmuştur. Değerler okunduktan sonra eşitlikler kullanılarak 1sıl yük hesaplamaları gerçekleştirilmiştir. Psikrometrik diyagramdan okunan değerler ve yapılan hesaplamaların sonuçları Tablo 7'de verilmiştir.

Tablo 7. Isı tekeri sistemi hesaplama sonuçları

\begin{tabular}{cccccccccc}
\hline Deney No & $\mathbf{1}$ & $\mathbf{2}$ & $\mathbf{3}$ & $\mathbf{4}$ & $\mathbf{5}$ & $\mathbf{6}$ & $\mathbf{7}$ & $\mathbf{8}$ & $\mathbf{9}$ \\
\hline $\mathbf{h}_{\mathbf{2}}(\mathbf{k j} / \mathbf{k g})$ & 61,0 & 53,0 & 59,0 & 53,8 & 53,0 & 54,0 & 52,0 & 53,0 & 54,3 \\
$\mathbf{h}_{\mathbf{3}}(\mathbf{k j} / \mathbf{k g})$ & 52,0 & 42,0 & 43,0 & 41,5 & 37,0 & 47,0 & 39,0 & 45,1 & 46,0 \\
$\mathbf{h}_{\mathbf{1 0}}(\mathbf{k j} / \mathbf{k g})$ & 48,7 & 39,0 & 49,0 & 39,0 & 39,0 & 40,0 & 39,0 & 39,8 & 40,0 \\
$\mathbf{h}_{11}(\mathbf{k j} / \mathbf{k g})$ & 58,0 & 49,0 & 56,0 & 49,0 & 49,0 & 50,0 & 47,2 & 49,0 & 52,0 \\
$\mathbf{V}_{\mathbf{g t}}\left(\mathbf{m}^{\mathbf{3}} / \mathbf{k g}\right)$ & 0,901 & 0,892 & 0,897 & 0,893 & 0,891 & 0,892 & 0,891 & 0,891 & 0,892 \\
$\mathbf{V}_{\mathbf{g e}}\left(\mathbf{m}^{\mathbf{3}} / \mathbf{k g}\right)$ & 0,899 & 0,879 & 0,889 & 0,879 & 0,879 & 0,882 & 0,897 & 0,882 & 0,887 \\
$\boldsymbol{Q}_{\mathbf{1}}(\mathbf{k j} / \mathbf{s})$ & 0,252 & 0,338 & 0,688 & 0,360 & 0,592 & 0,343 & 0,367 & 0,316 & 0,365 \\
$\dot{\boldsymbol{Q}}_{\mathbf{2}}(\mathbf{k j} / \mathbf{s})$ & 0,177 & 0,296 & 0,238 & 0,32 & 0,41 & 0,14 & 0,320 & 0,138 & 0,324 \\
$\boldsymbol{\eta} \mathbf{( \% )}$ & 70 & 87 & 34 & 90 & 69 & 40 & 87 & 43 & 90 \\
\hline
\end{tabular}

Tüm parametrelerin, ısı tekeri ısıl verimliliği üzerindeki etkisinin araştırılması için Taguchi tarafından belirlenen Sinyal/Gürültü $(\mathrm{S} / \mathrm{N})$ oranları hesaplanarak, ANOVA analizi yapılmıştır. Yapılan deneyler sonucunda elde edilen veriler ile hesaplanan isıl verimlilik değerleri ve bunların 'en büyük-en iyi' yaklaşımına göre hesaplanan S/N oranları Tablo 8'de verilmiştir. En-büyük-en-iyi yaklaşımıyla S/N oranının hesaplanması Denklem (4.1) ile gerçekleştirilmiştir (Karanfil, 2020).

$S / N=-10 \log \left(\frac{1}{n} \sum_{i=1}^{N} \frac{1}{y_{i}^{2}}\right)$

Tablo 8. Isı tekeri sisteminin S/N oranlarl

\begin{tabular}{lccccc}
\hline & A & B & C & Verim $\mathbf{( \% )}$ & S/N \\
\hline $\mathbf{1}$ & 60 & 60 & 60 & 70 & 36,90 \\
$\mathbf{2}$ & 60 & 80 & 80 & 87 & 38,79 \\
$\mathbf{3}$ & 60 & 100 & 100 & 34 & 30,63 \\
$\mathbf{4}$ & 80 & 60 & 80 & 90 & 39,08 \\
$\mathbf{5}$ & 80 & 80 & 100 & 69 & 36,78 \\
$\mathbf{6}$ & 80 & 100 & 60 & 40 & 32,04 \\
$\mathbf{7}$ & 100 & 60 & 100 & 87 & 38,79 \\
$\mathbf{8}$ & 100 & 80 & 60 & 43 & 32,67 \\
$\mathbf{9}$ & 100 & 100 & 80 & 90 & 38,99 \\
\hline
\end{tabular}

Taguchi analizi ile her bir parametre için S/N oranları hesaplanıp, her bir parametrenin 1Sı tekeri 1sıl verimliliği üzerindeki etkisi araştırılmıştır. Parametrelerin optimum seviyelerinin belirlenmesi için oluşturulan S/N grafiği Şekil 2'de verilmiştir. Elde edilen grafiklerden yola çıkarak optimum koşullar; 1S1 tekeri için A3B1C2 olarak belirlenmiştir. Sonuç olarak doğrulama deneyinin 1sı tekeri için \% 100 ısı tekeri devir hızı, \% 60 Fan 1 hızı ve \% 80 Fan 2 hızı şartlarında gerçekleştirileceği belirlenmiştir. 


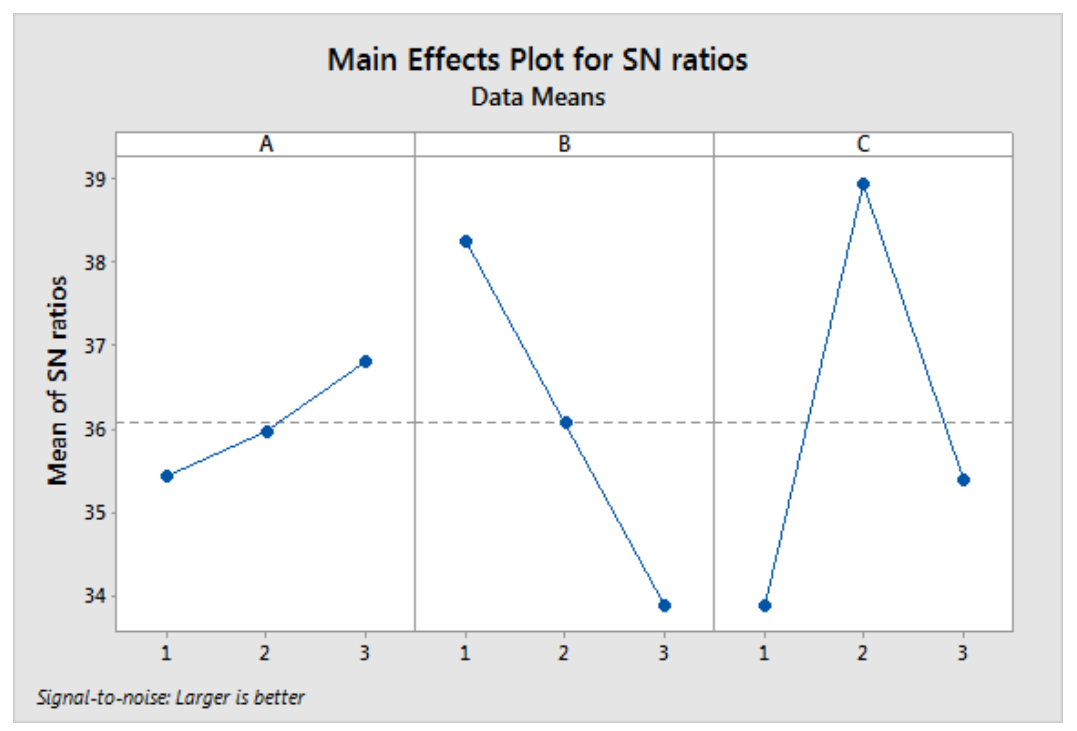

Şekil 2. Isı tekeri S/N orani grafikleri

Belirlenen parametrelerin ve seviyelerinin 1S1 tekeri sisteminin 1 sıl verimliliği üzerindeki etkisinin araştırılması için $\mathrm{S} / \mathrm{N}$ oranı tablosu ve ANOVA analizi gerçekleştirilmiş̧ir. Sonuçlar sırasıyla Tablo 9 ve Tablo 10'da verilmiş̧ir.

Tablo 9. Isı tekeri verimliliğinin $S / N$ oranları

\begin{tabular}{llll}
\hline Seviye & A & B & C \\
\hline $\mathbf{1}$ & 35,44 & 38,26 & 33,87 \\
$\mathbf{2}$ & 35,97 & 36,08 & 38,95 \\
$\mathbf{3}$ & 36,82 & 33,89 & 35,40 \\
Delta & 1,38 & 4,37 & 5,08 \\
Kademe & 3 & 2 & 1 \\
\hline
\end{tabular}

Tablo 10. Isl tekeri verimliliğinin ANOVA analizi

\begin{tabular}{lllll}
\hline Parametre & $\begin{array}{l}\text { Serbestlik } \\
\text { Derecesi }\end{array}$ & Kareler Toplamı & Varyans & F-değeri \\
\hline $\mathbf{A}$ & 2 & 138,7 & 69,33 & 0,20 \\
B & 2 & 1184,0 & 592,00 & 1,74 \\
C & 2 & 2212,7 & 1106,33 & 3,25 \\
Hata & 2 & 680,7 & 340,33 & \\
Toplam & 8 & 4216,0 & & \\
\hline
\end{tabular}

S/N oranları ve ANOVA analizi sonuçlarına göre 1sı tekeri verimliliğinde en etkili faktör Fan 2 hızı, yani taze hava hızıdır. Bunu sırayla Fan 1 hızı ve 1sı tekeri devir hızı takip etmektedir.

Taguchi analizi sonucunda optimum koşullar; A3B1C2 olarak belirlenmiştir. Bu şartlarda gerçekleştirilen doğrulama deneyinin verileri ve psikrometrik diyagramdan okunan değerleri ile hesaplanan 1sıl yükleri Tablo 11 ve 12 'de sırasıyla verilmiştir.

Tablo 11. Isı tekeri doğrulama deneyi ölçüm sonuçları

\begin{tabular}{ll}
\hline Doğrulama Deneyi & \\
\hline $\mathbf{T}_{\mathbf{2}}\left({ }^{\mathbf{C}} \mathbf{C}\right)$ & 40,6 \\
$\mathbf{H}_{\mathbf{2}}(\mathbf{\%})$ & 14,6 \\
$\mathbf{T}_{\mathbf{3}}\left({ }^{\circ} \mathbf{C}\right)$ & 26,7 \\
$\mathbf{H}_{\mathbf{3}}(\mathbf{\%})$ & 32,0 \\
$\mathbf{T}_{\mathbf{1 0}}\left({ }^{\circ} \mathbf{C}\right)$ & 24,8 \\
$\mathbf{H}_{\mathbf{1 0}}(\mathbf{\%})$ & 35,1 \\
$\mathbf{T}_{\mathbf{1 1}}\left({ }^{\circ} \mathbf{C}\right)$ & 37,4 \\
$\mathbf{H}_{1 \mathbf{1}}(\mathbf{\%})$ & 18,1 \\
$\mathbf{u}_{\mathbf{t}}(\mathbf{m} / \mathbf{s})$ & 0,57 \\
$\mathbf{u}_{\mathbf{e}}(\mathbf{m} / \mathbf{s})$ & 0,59 \\
\hline
\end{tabular}


Tablo 12. Isı tekeri doğrulama deneyi hesaplama sonuçları

\begin{tabular}{|c|c|}
\hline \multicolumn{2}{|c|}{ Doğrulama Deneyi } \\
\hline$h_{2}(\mathbf{k j} / \mathbf{k g})$ & 59,0 \\
\hline$h_{3}(\mathbf{k j} / \mathbf{k g})$ & 47,0 \\
\hline$h_{10}(\mathrm{kj} / \mathrm{kg})$ & 44,0 \\
\hline$h_{11}(\mathbf{k j} / \mathbf{k g})$ & 56,0 \\
\hline$v_{g t}\left(\mathbf{m}^{3} / \mathbf{k g}\right)$ & 0,899 \\
\hline Vge $\left(\mathbf{m}^{3} / \mathbf{k g}\right)$ & 0,899 \\
\hline$\dot{Q}_{1}(\mathbf{k j} / \mathbf{s})$ & 0,348 \\
\hline$\dot{Q}_{2}(\mathrm{kj} / \mathrm{s})$ & 0,336 \\
\hline$\eta(\%)$ & 97 \\
\hline
\end{tabular}

Optimum koşullar altında gerçekleştirilen deneyde 1sıl verim \% 97 olarak bulunmuş ve bu değer elde edilen en yüksek verim olarak kaydedilmiştir (Ener Rusen vd., 2017a). Antonellis ve ark. (2014) yaptıkları çalışmada duyulur verimliliği maksimum, basınç düşüşünü ise minimum yapmak için ısı tekerlerinin ayrıntılı bir optimizasyonunu gerçekleştirmişlerdir. Optimizasyon çalışmasını, 1sı tekeri uzunluğu, kanal tabanı, yükseklik ve kalınlık gibi ana tasarım parametrelerinin değişimi ile farklı çalışma koşulları için, yani hava yüzeyi hızı ve devir sayısı ile gerçekleştirmişlerdir. Yapılan deneyler sonucunda maksimum 1sı tekeri duyulur verimini \% 79 olarak bulmuşlar ve optimizasyon çalışması ile \% 83 civarlarına çıkarmışlardır. Wallin ve Claesson (2014) yaptıkları çalışmada 1sı tekerinin kullanıldığı bir hava kontrol ünitesinde 1sı pompası kullanarak 1sı geri kazanımını arttırmayı amaçlamışlardır. Yapılan çalışmada 1sı tekerinin 1sıl verimi \% 63 olarak bulunurken, toplam ısıl verimlilik \% 87 olarak hesaplanmıştır. Isı pompası, kompresör ve 1sı tekerinin baz alındığı tüm sistemin ısıl verimi ise \% 97 olarak belirlenmiştir. Çalışmalarımızda kullanılan sistemin daha küçük kapasiteli olması ve kayıplarının minimuma indirgenmiş olması sebebiyle daha yüksek verimliliğe sahip olması mantıklı bir sonuç olmakla birlikte literatürle uyumluluk da göstermektedir.

\subsection{Reküparatörün Isıl Verimlilik Sonuçları}

Reküparatör sistemi için Taguchi optimizasyon metodu ile belirlemiş olan deney tasarımı neticesinde gerçekleştirilen deneylerin ölçüm sonuçları Tablo 13'te verilmiştir. Tablodaki T ve H sırasıyla, Şekil 1'de verilen noktalardaki kuru termometre sıcaklıklarını ve bağıl nemleri göstermektedir. $u_{t}$ taze hava hızını ve $u_{e}$ egzoz hava hızını vermektedir.

Tablo 13. Reküparatör sistemi ölçüm sonuçları

\begin{tabular}{|c|c|c|c|c|c|c|c|c|c|}
\hline Deney no & 1 & 2 & 3 & 4 & 5 & 6 & 7 & 8 & 9 \\
\hline Hava Giriş Sıcaklığı $\left({ }^{\circ} \mathrm{C}\right)$ & 30 & 30 & 30 & 40 & 40 & 40 & 50 & 50 & 50 \\
\hline Fan1 Hızı (\%) & 60 & 80 & 100 & 60 & 80 & 100 & 60 & 80 & 100 \\
\hline Fan2 Hizı (\%) & 60 & 80 & 100 & 80 & 100 & 60 & 100 & 60 & 80 \\
\hline $\mathrm{T}_{5}\left({ }^{\circ} \mathrm{C}\right)$ & 30,6 & 30,6 & 30,6 & 38,8 & 39,9 & 40,6 & 49,3 & 49,1 & 48,0 \\
\hline $\mathrm{H}_{5}(\%)$ & 20,8 & 21 & 21,6 & 11,5 & 11,1 & 10,9 & 9,4 & 9,4 & 9,8 \\
\hline $\mathrm{T}_{6}\left({ }^{\circ} \mathrm{C}\right)$ & 28,2 & 28,6 & 28,6 & 30,3 & 32,5 & 36,5 & 34,7 & 42,3 & 41,5 \\
\hline $\mathrm{H}_{6}(\%)$ & 23,5 & 23,1 & 23,6 & 17,6 & 15,8 & 13,0 & 18,9 & 12,7 & 13,2 \\
\hline $\mathbf{T}_{7}\left({ }^{\circ} \mathbf{C}\right)$ & 26,5 & 27,0 & 27,2 & 25,2 & 26,2 & 26,5 & 27,1 & 28,3 & 29,1 \\
\hline $\mathrm{H}_{7}(\%)$ & 25,9 & 25,7 & 26,0 & 23,6 & 22,7 & 22,5 & 27,5 & 26,9 & 25,3 \\
\hline $\mathrm{T}_{8}\left({ }^{\circ} \mathrm{C}\right)$ & 28,9 & 28,9 & 29,0 & 32,1 & 33,3 & 36,5 & 37,6 & 42,8 & 41,0 \\
\hline $\mathrm{H}_{8}(\%)$ & 22,5 & 23,0 & 23,5 & 16,1 & 15,4 & 13,2 & 15,7 & 12,7 & 13,5 \\
\hline $\mathbf{u}_{t}(\mathbf{m} / \mathbf{s})$ & 0,31 & 0,54 & 0,64 & 0,54 & 0,70 & 0,28 & 0,72 & 0,26 & 0,54 \\
\hline $\mathbf{u}_{\mathrm{e}}(\mathbf{m} / \mathbf{s})$ & 0,53 & 0,77 & 0,82 & 0,67 & 0,96 & 1,24 & 0,68 & 1,09 & 1,13 \\
\hline
\end{tabular}

Taguchi optimizasyon metodu ile oluşturan deney tasarımı neticesinde, belirlenen parametreler ve seviyelerine göre deneyler gerçekleştirilmiş ve elde edilen veriler doğrultusunda psikrometrik diyagram kullanılarak entalpi ve özgül hacim değerleri okunmuştur. Değerler okunduktan sonra eşitlikler kullanılarak ısıl yük hesaplamaları gerçekleştirilmiştir. Psikrometrik diyagramdan okunan değerler ve yapılan hesaplamaların sonuçları Tablo 14 'te verilmiştir. 
European Journal of Science and Technology

Tablo 14. Reküparatör sistemi hesaplama sonuçları

\begin{tabular}{cccccccccc}
\hline Deney No & $\mathbf{1}$ & $\mathbf{2}$ & $\mathbf{3}$ & $\mathbf{4}$ & $\mathbf{5}$ & $\mathbf{6}$ & $\mathbf{7}$ & $\mathbf{8}$ & $\mathbf{9}$ \\
\hline $\mathbf{h}_{\mathbf{5}}(\mathbf{k j} / \mathbf{k g})$ & 45,8 & 46,0 & 46,5 & 53,0 & 54,0 & 56,0 & 69,0 & 67,5 & 67,0 \\
$\mathbf{h}_{\mathbf{6}}(\mathbf{k j} / \mathbf{k g})$ & 42,5 & 43,0 & 43,5 & 43,0 & 45,0 & 48,0 & 51,0 & 60,0 & 58,0 \\
$\mathbf{h}_{\mathbf{7}}(\mathbf{k j} / \mathbf{k g})$ & 40,0 & 42.0 & 43,0 & 37,0 & 39,0 & 41,0 & 44,5 & 45,0 & 46,5 \\
$\mathbf{h}_{\mathbf{8}}(\mathbf{k j} / \mathbf{k g})$ & 43,5 & 44,0 & 44,5 & 45,0 & 46,5 & 49.0 & 54,0 & 59,0 & 58,0 \\
$\mathbf{v}_{\mathbf{g t}}\left(\mathbf{m}^{\mathbf{3}} / \mathbf{k g}\right)$ & 0,863 & 0,862 & 0,863 & 0,871 & 0,874 & 0,883 & 0,888 & 0,902 & 0,898 \\
$\mathbf{v}_{\mathbf{g e}}\left(\mathbf{m}^{\mathbf{3}} / \mathbf{k g}\right)$ & 0,866 & 0,868 & 0,869 & 0,890 & 0,894 & 0,895 & 0,922 & 0,924 & 0,918 \\
$\boldsymbol{Q}_{\mathbf{1}}(\mathbf{k j} / \mathbf{s})$ & 0,089 & 0,118 & 0,125 & 0,333 & 0,428 & 0,490 & 0,587 & 0,391 & 0,490 \\
$\dot{\boldsymbol{Q}}_{\mathbf{2}}(\mathbf{k j} / \mathbf{s})$ & 0,055 & 0,055 & 0,049 & 0,219 & 0,232 & 0,112 & 0,341 & 0,179 & 0,306 \\
$\boldsymbol{\eta} \mathbf{( \% )}$ & 62 & 47 & 39 & 65 & 54 & 23 & 58 & 45 & 62 \\
\hline
\end{tabular}

Tüm parametrelerin, reküparatörün $1 s ı$ verimliliği üzerindeki etkisinin araştırılması için Taguchi tarafından belirlenen Sinyal/Gürültü (S/N) oranları hesaplanarak, ANOVA analizi yapılmıştır. Yapılan deneyler sonucunda elde edilen veriler ile hesaplanan 1sıl verimlilik değerleri ve bunların 'en büyük-en iyi' yaklaşımına göre hesaplanan S/N oranları Tablo 15 'te verilmiştir. En-büyük-eniyi yaklaşımıyla $\mathrm{S} / \mathrm{N}$ oranının hesaplanması Eşitlik 4.1 ile gerçekleştirilmiştir.

Tablo 15. Reküparatör sisteminin S/N oranlarl

\begin{tabular}{cccccc}
\hline & A & B & C & Verim (\%) & S/N \\
\hline 1 & 30 & 60 & 60 & 62 & 35,84 \\
2 & 30 & 80 & 80 & 47 & 33,44 \\
3 & 30 & 100 & 100 & 39 & 31.82 \\
4 & 40 & 60 & 80 & 65 & 36,25 \\
5 & 40 & 80 & 100 & 54 & 34,64 \\
6 & 40 & 100 & 60 & 23 & 27,23 \\
7 & 50 & 60 & 100 & 58 & 35,26 \\
8 & 50 & 80 & 60 & 45 & 33,06 \\
9 & 50 & 100 & 80 & 62 & 35,84 \\
\hline
\end{tabular}

Taguchi analizi ile her bir parametre için $\mathrm{S} / \mathrm{N}$ oranları hesaplanıp, her bir parametrenin reküparatör 1sıl verimliliği üzerindeki etkisi araştırılmıştır. Parametrelerin optimum seviyelerinin belirlenmesi için oluşturulan S/N grafiği Şekil 3’te verilmiştir. Elde edilen grafiklerden yola çıkarak optimum koşullar; reküparatör için A3B1C2 olarak belirlenmiştir. Sonuç olarak doğrulama deneyinin reküparatör için $50^{\circ} \mathrm{C}$ sıcaklık, \% 60 Fan 1 hızı ve \% 80 Fan 2 hızı şartlarında gerçekleştirileceği belirlenmiştir.

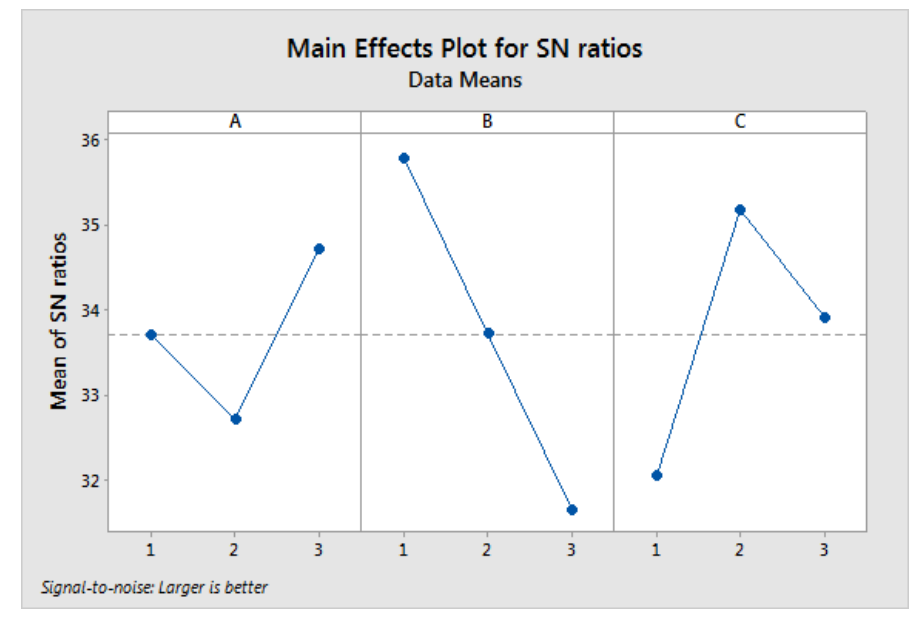

Şekil 3. Reküparatör S/N oranı grafikleri

Belirlenen parametrelerin ve seviyelerinin reküparatör sisteminin 1sıl verimliliği üzerindeki etkisinin araştırılması için $\mathrm{S} / \mathrm{N}$ oranı tablosu ve ANOVA analizi gerçekleştirilmiştir. Sonuçlar sırasıyla Tablo 16 ve 17'de verilmiştir. 
Avrupa Bilim ve Teknoloji Dergisi

Tablo 16. Reküparatör verimliliğinin S/N oranlart

\begin{tabular}{llll}
\hline Seviye & A & B & C \\
\hline 1 & 33,70 & 35,79 & 32,05 \\
2 & 32,71 & 33,72 & 35,18 \\
3 & 34,73 & 31,63 & 33,91 \\
Delta & 2,01 & 4,16 & 3,13 \\
Kademe & 3 & 1 & 2 \\
\hline
\end{tabular}

Tablo 17. Reküparatör verimliliğinin ANOVA analizi

\begin{tabular}{lllll}
\hline Parametre & $\begin{array}{l}\text { Serbestlik } \\
\text { Derecesi }\end{array}$ & Kareler Toplamı & Varyans & F-değeri \\
\hline A & 2 & 94,89 & 47,44 & 0,23 \\
B & 2 & 636,22 & 318,11 & 1,51 \\
C & 2 & 322,89 & 161,44 & 0,77 \\
Hata & 2 & 420,22 & 210,11 & \\
Toplam & 8 & 1474,22 & & \\
\hline
\end{tabular}

$\mathrm{S} / \mathrm{N}$ oranları ve ANOVA analizi sonuçlarına göre reküparatör verimliliğginde en etkili faktör Fan 1 hızı, yani egzoz havası hızıdır. Bunu sırayla Fan 2 hızı ve sıcaklık takip etmektedir.

Taguchi analizi sonucunda optimum koşullar; A3B1C2 olarak belirlenmiştir. Bu şartlarda gerçekleştirilen doğrulama deneyinin verileri ve psikrometrik diyagramdan okunan değerleri ile hesaplanan ssıl yükleri Tablo 18 ve 19'da sirasıyla verilmiştir.

Tablo 18. Reküparatör doğrulama deneyi ölçüm sonuçları

\begin{tabular}{lc}
\hline Doğrulama Deneyi & \\
\hline $\mathbf{T}_{\mathbf{5}}\left({ }^{\mathbf{O}} \mathbf{C}\right)$ & 50,5 \\
$\mathbf{H}_{\mathbf{5}}(\mathbf{\%})$ & 6,3 \\
$\mathbf{T}_{\mathbf{6}}\left({ }^{\circ} \mathbf{C}\right)$ & 37,4 \\
$\mathbf{H}_{\mathbf{6}}(\mathbf{\%})$ & 11,7 \\
$\mathbf{T}_{\mathbf{7}}\left({ }^{\mathbf{O}} \mathbf{C}\right)$ & 27,2 \\
$\mathbf{H}_{\mathbf{7}}(\mathbf{\%})$ & 20,2 \\
$\mathbf{T}_{\mathbf{8}}\left({ }^{(} \mathbf{C}\right)$ & 39,7 \\
$\mathbf{H}_{\mathbf{8}}(\mathbf{\%})$ & 10,6 \\
$\mathbf{u}_{\mathbf{t}}(\mathbf{m} / \mathbf{s})$ & 0,36 \\
$\mathbf{u}_{\mathbf{e}}(\mathbf{m} / \mathbf{s})$ & 0,71 \\
\hline
\end{tabular}

Tablo 19. Reküparatör doğrulama deneyi hesaplama sonuçları

\begin{tabular}{|c|c|}
\hline \multicolumn{2}{|c|}{ Doğrulama Deneyi } \\
\hline$h_{5}(\mathbf{k j} / \mathbf{k g})$ & 67 \\
\hline$h_{6}(\mathbf{k j} / \mathbf{k g})$ & 52 \\
\hline $\mathbf{h}_{7}(\mathbf{k j} / \mathbf{k g})$ & 40 \\
\hline$h_{8}(\mathbf{k j} / \mathbf{k g})$ & 53 \\
\hline $\mathrm{Vgt}\left(\mathrm{m}^{3} / \mathbf{k g}\right)$ & 0,888 \\
\hline Vge $\left(\mathbf{m}^{3} / \mathbf{k g}\right)$ & 0,921 \\
\hline$\dot{Q}_{1}(\mathrm{kj} / \mathrm{s})$ & 0,511 \\
\hline$\dot{Q}_{2}(\mathrm{kj} / \mathrm{s})$ & 0,376 \\
\hline$\eta(\%)$ & 73 \\
\hline
\end{tabular}

Optimum koşullar altında gerçekleştirilen deneyde 1 sıl verim \% 73 olarak bulunmuş ve bu değer elde edilen en yüksek verim olarak kaydedilmiştir (Ener Rusen vd., 2017b). İlten ve ark. (2019) yaptıkları çalışmada 1sı pompası destekli ısı geri kazanım cihazının deneysel çalışmalarını incelemiş ve oluşan hataların sistem üzerine etkisini araştırmışlardır. Kış koşullarında (ısıtma durumunda) reküparatörün etkinliğini \% 70 civarında bulmuşlardır.

\section{Sonuç}

Atık 1Sı geri kazanımı için kullanılan 1sı tekeri ve reküparatörün 1sıl verimlerinin üzerindeki etkin parametrelerin belirlenmesi için yapılan bu çalışmada, atık 1 sı geri kazanım şartları Taguchi metodu ile optimize edilerek, deneyler $\mathrm{L}_{9}$ ortogonal dizinde gerçekleştirilmiştir. Yapılması gereken deney sayısı Taguchi metodu ile 9 olarak belirlenmiş ve optimum sonuçlar elde edilecek şekilde minumum deney sayısı ile analizler yapılmıştır. Analizler için geleneksel yönteme göre 18 deney daha az yapılarak zaman ve maliyet tasarrufu yapılmıştır. Isıl verimlilik hesaplamalarının yapılması için deneyler sonucunda elde edilen değerler kullanılarak psikrometrik 
diyagramdan entalpi ve özgül hacim değerleri okunmuştur. Denklemler kullanılarak hesaplanan 1sıl verimler arasında, optimum atık 1S1 geri kazanım koşullarının belirlenmesi için Taguchi S/N oranı ve ANOVA analizi gerçekleştirilmiştir. Optimum koşullar 1sı tekeri için A3B1C2 (\% 100 1sı tekeri devir hızı, \% 60 Fan 1 hızı ve \% 80 Fan 2 hızı) ve reküparatör için A3B1C2 $\left(50{ }^{\circ} \mathrm{C}\right.$ sıcaklık, $\% 60$ Fan 1 hızı ve \% 80 Fan 2 hızı) olarak bulunmuştur. Isı tekeri için en etkin parametre Fan 2 hızı yani taze hava hızı olarak bulunurken, reküparatör için en etkin parametere Fan 1 hızı yani egzoz havası hızıdır. Doğrulama deneyleri sonucunda elde edilen en yüksek verim değerleri 1sı tekeri ve reküparatör sistemleri için sırasıyla $\% 97$ ve \% 73 olarak bulunmuştur. Bu değerler, yapılan tüm deneyler içerisinde en yüksek verim değerleri olarak kaydedilmiştir. Bu durum yapılan analizlerin doğruluğunu kanıtlamakta ve ileride yapılacak çalışmalara işık tutmaktadır.

\section{Teşekkür}

$\mathrm{Bu}$ çalışmanın gerçekleştirildiği sistemin alınmasına TR52/15/YNRKG1/0013 proje numarası ile finansal destek sağlayan Mevlana Kalkınma Ajansı'na (MEVKA) ve Karamanoğlu Mehmetbey Üniversitesi’ne teşekkür ederiz.

\section{Kaynakça}

Antonellis, S., Intini, M., Joppolo, C.M., Leone, C., 2014. "Design optimization of heat wheels for energy recovery in HVAC systems", Energies, 7, 7348-7367.

Brueckner, S., Miro, L., Cabeza, L.F., Pehnt, M., Laevemann, E., 2014. "Methods to estimate the industrial waste heat potential of regions - A categorization and literature review", Renewable and Sustainable Energy Reviews, 38, 164-171.

Çengel, Y.A., 2011. "Isı ve Kütle Transferi-Pratik Bir Yaklaşım”, Üçüncü Baskı, Güven Bilimsel, İzmir Güven Kitabevi, İzmir.

Çomakli, K. ve Terhan, M., 2011. "Sıcak su üretimi için baca gazı atık enerjinin kullanımı", Tesisat Mühendisliği Dergisi, 124, 43-51.

Editorial, 2018. "Editorial: Industrial waste heat recovery", Energy, 160, 1-2.

Ener Rusen, S. ve Koç, M. 2019. "Enerji Tüketim ve $\mathrm{CO}_{2}$ Salınım Değerlerinin Analizi; Bir Gıda Fabrikası Örneği”, BEÜ Fen Bilimleri Dergisi, 8 (4), 1478-1488.

Ener Rusen, S., 2019. "Elektrik Motorlarının Verimlilik ve $\mathrm{CO}_{2}$ Emisyon Analizi; Bir Gıda Fabrikası Örneği”, Avrupa Bilim ve Teknoloji Dergisi, 17, 564-569.

Ener Rusen, S., Topcu, M.A., Celtek, S.A., Karanfil, G. ve Rusen, A. 2018. "Investigation of energy saving potentials of a food factory by energy audit", Journal of Engineering Research and Applied Science, 7 (1), 848-860.

${ }^{a}$ Ener Rusen, S., Karanfil Celep, G., Poyraz, Ş. N., 2017. "Optimization of system parameters of heat wheel to enhance the thermal efficiency using Taguchi optimization method”, Internatıonal Conference on Energy and Thermal Engineering: İstanbul 2017, 281.

${ }^{b}$ Ener Rusen, S., Karanfil Celep, G., Can, M., 2017. "Influence of Inlet Temperature and Flow Rate of Air on The Thermal Yield of Recuperator", International Conference on Energy and Thermal Engineering: İstanbul 2017, 279.

http://kmu.edu.tr/akademikenerji

İlten, N., Muslu, M., Caner, İ., 2019. "Isı pompası destekli 1sı geri kazanım cihazında kullanılan parametrelerin hata analizleri”, BAUN Fen Bilimleri Enstitüsü Dergisi, 21 (1), 53-62.

Jouhara, H., Khordehgah, N., Almahmoud, S., Delpech, B., Chauhan, A., Tassou, S.A., 2018. "Waste heat recovery technologies and applications", Thermal Science and Engineering Progress, 6, 268-289.

Karanfil, G., Ener Rusen, S., Topcu, M.A., Çeltek, S.A. ve Rusen, A., 2019. "Application of Recuperator for Waste Heat Recovery from Exhaust Flue Gas in Hot Water Boiler in a Central Heating Plant”, Eskişehir Technical University Journal of Science and Technology A- Applied Sciences and Engineering, 20(1), 112-120.

Karanfil, G., 2020. "Importance and applications of DOE/optimization methods in PEM fuel cells: A review", International Journal of Energy Research, 44, 4-25.

Manikantha, J.T., Krishna, A.R., Phanisankar, B.S.S., 2017. "Effect on Performance and Emission Characteristics of C.I Engine by Preheating of Intake Air Using Heat Wheel", International Journal of Thermal Technologies, 7(4), 211-222.

Oğulata, R.T., 2004. "Utilization of waste-heat recovery in textile drying", Applied Energy, 79, 41-49.

Shahsavar, A. ve Khanmohammadi, S., 2019. "Energy and economic evaluation and multicriteria optimization of different arrangements of integrated photovoltaic thermal and heat recovery wheel system", International Journal of Energy Research, 1-18.

Uysal, H. L., 2019. "Endüstriyel boyahane tesislerinde baca gazı atık 1sısının geri kazanım analizi ve bir uygulama", Yüksek lisans tezi, Fen Bilimleri Enstitüsü, Makine Mühendisliği Anabilim Dalı, Balıkesir Üniversitesi.

Wallin, J. and Claesson, J., 2014. "Improving heat recovery using retrofitted heat pump in air handling unit with energy whell", Applied Thermal Engineering, 62, 823-829.

Varga, Z. ve Palotai, B., 2017. “Comparison of low temperature waste heat recovery methods”, Energy, 137, 1286-1292. 